\begin{tabular}{|l|l|l|}
\hline \multirow{4}{*}{$\begin{array}{l}\text { INTERNATIONAL } \\
\text { ENGINEERING, } \\
\text { SCIENCE AND } \\
\text { EDUCATION } \\
\text { INESEG }\end{array}$} & $\begin{array}{l}\text { Middle East Journal of Science } \\
\text { GROUP }\end{array}$ & $\begin{array}{l}\text { Published online August 28, 2017 } \\
\text { doi: } 10.23884 / \text { mejs.2017.3.1.07 } \\
\text { ISSN: } 2536-5312\end{array}$ \\
\hline
\end{tabular}

\title{
OUT-OF-MIND INHIBITORS OF HUMAN SERUM PARAOXONASE 1 (PON1): AN IN VITRO STUDY
}

\author{
Mustafa Oguzhan Kaya
}

\author{
Siirt University, Faculty of Veterinary Medicine, Div. Basic Sciences, Dep. of \\ Biochemistry, Siirt, Turkey
}

\begin{abstract}
: 4-(dimethylamino)benzaldehyde, 3,5-dinitrosalicylic acid, berylliumsulfate tetrahydrate, urea, sodium azide, iron(II)sulfateheptahydrate, 2-thiobarbituric acid, benzidine, and hydrazinium sulfate, which are commonly used in the pharmaceutical industry and medical studies, have been examined as novel type of inhibitors of PON1. PON1 was purified by hydrophobic column of Sepharose4B-coupled L-tyrosine- 1-naphthylamine. PON1 enzyme activity towards paraoxon substrate was quantified spectrophotometrically. A critical overview of the effects of these nine reagents on PON1 which associated with cardiovascular diseases has been given. The IC $C_{50}$ values were between $1.26 \times 10^{-}$ ${ }^{4} \mathrm{M}$ and $2.31 \times 10^{-4} \mathrm{M}$ and benzidine showed the best inhibitory effect $\left(\mathrm{IC}_{50}=1.26 \times 10^{-4} \mathrm{M}\right)$ for PON1 enzyme activity.
\end{abstract}

Key Words: Cardiovascular disease, PON1, Antioxidant activity, Inhibition, HDL-C, LDL-C

Corresponding Author: Dr. Mustafa Oğuzhan Kaya E-mail: m.oguzhankaya@gmail.com

\section{Introduction}

Paraoxonase 1 (PON1) has relation with high-density lipoproteins (HDL). PON1 is synthesized by liver and discharged in the blood stream [1,2]. PON1 is an antioxidant enzyme due to the its antioxidant activity. PON1 has an ability to hydrolyze lipid peroxides, catalyzing the breakdown of oxidized phospholipids from low-density lipoprotein (LDL) [3]. For this reason, PON1 has an significant responsibility for lipid metabolism, preventing atherosclerotic plaque formation $[4,5]$. Patients with cardiovascular diseases (CVD) are seen to have lower serum PON1 activity [6].

Coronary artery disease (CAD) and other associated diseases are main causes of morbidity and mortality in different regions of the world $[7,8]$. The onset of these diseases is associated with the presence of atherosclerosis, a chronic disease with multifactorial etiology $[9,10]$. Among the factors contributing to risk for CVD, dyslipidemia has been shown to be common and its relation with other factors substantially increases the risk of developing cardiovascular diseases [11].

With regards to genetic impacts on coronary heart disease progress, there is evidence defining that changes in paraoxonase family (PON) genes conduce to CVD pathogenesis [12-14]. It has been demonstrated by studies that the paraoxonase1 (PON1) enzyme is related to the inhibition of lipid peroxidation of high-density lipoprotein cholesterol (HDL-C), reduced oxidative modification of lowdensity lipoprotein cholesterol (LDL-C) [15,16], and protection of HDL-C and LDL-C function $[17,18]$. Serum PON1 activity is an inversely proportional to CVD in that individuals with diseases of the carotid artery or coronary and myocardial infarction display lower PON1 activity [14,15]. Thus, PON1 has been detected as a candidate gene that may explain individual propensity for CVD [16,17]. 
In this study, nine compounds which are commonly used in the pharmaceutical industry and medical studies were used, and their inhibitory impacts on purified human serum PON1 activity were evaluated.

\section{Materials and Methods}

The materials used including sepharose 4B, L-tyrosine, 1-napthylamine, paraoxon, protein assay reagents were obtained from Sigma Chem. Co. All. chemicals used were analytical grade.

\subsection{Purification of PON1 enzyme from human serum}

Blood samples were taken from those who were healthy and voluntary. Human serum was insulated from fresh human blood collected in a tube which was dry. The blood samples were centrifuged at $26916 \mathrm{~g}$ for $15 \mathrm{~min}$ and the serum was recovered. Initially, crude serum PON1 was insulated by ammoniumsulfate precipitation (60-80\% fraction) [19]. The precipitate was collected by centrifugation at $26916 \mathrm{~g}$ for $20 \mathrm{~min}$. and then redissolved in $100 \mathrm{mM}$ Tris- $\mathrm{HCl}$ buffer (pH 8.0) [20].

Then, hydrophobic interaction chromatography was applied to crude PON1 solution on a hydrophobic column of Sepharose-4B-coupled L-tyrosine- 1-naphthylamine, synthesized according to Sinan et al.[19]. The paraoxonase was eluted with ammonium sulfate gradient using $0.1 \mathrm{M} \mathrm{Na}_{2} \mathrm{HPO}_{4}$ buffer with and without ammonium sulfate $\mathrm{pH}$ 8.00. The purified PON1 enzyme was stocked with 2 $\mathrm{mM} \mathrm{CaCl} 2$ at $+4{ }^{\circ} \mathrm{C}$, so as to fulfill the activity $[19,20]$.

\subsection{Paraoxonase enzyme assay}

PON1 enzyme activity towards paraoxon substrate was quantified spectrophotometrically through the method defined by Gan et al.[21]. The reaction was followed for 2 min. at $37{ }^{\circ} \mathrm{C}$ by monitoring the appearance of p-nitrophenol at $412 \mathrm{~nm}$ in a Biotek automated recording spectrophotometer. A molar extinction coefficient $(\varepsilon)$ of $17100 \mathrm{M}^{-1} \mathrm{~cm}^{-1}$ for p-nitrophenol in $100 \mathrm{mM}$ Tris-base buffer ( $\mathrm{pH} 8.0)$ was applied to calculate. PON1 activity $\left(1 \mathrm{Ul}^{-1}\right)$ was described as $1 \mu \mathrm{mol}$ of $\mathrm{p}$ nitrophenol formed per minute [19-21].

\subsection{Data Analysis}

For studies related to inhibition of nine potential CVD preventing reagents (4(Dimethylamino)benzaldehyde, 3,5-Dinitrosalicylic Acid, Berylliumsulfate tetrahydrate, Urea, Sodium Azide, Iron(II)sulfateheptahydrate, 2-Thiobarbituric acid, Benzidine, Hydrazinium sulfate) as PON1 inhibitors different concentrations were added from stock solution $\left(10^{-3} \mathrm{M}\right)$ to the enzyme activity. Paraoxonase activity with these chemicals was assayed with the hydration of paraoxon followed. Activity values (\%) of paraoxonase related to six different concentrations of each these nine chemicals were determined through regression analysis using the Microsoft Office Excel as shown in the Figure1. Paraoxonase activity was accepted as $100 \%$ in the absence of these reagents and $\mathrm{IC}_{50}$ values of the mentioned reagents were obtained from the graphs.

\section{Results}

In this study, PON1 was purified from a crude ammonium sulfate precipitated fraction of human blood serum using a Sepharose 4B-L-tyrosine-1-naphthylamine hydrophobic interaction chromatography column.

To evaluate inhibitory effects of PON1, PON1 inhibition assays with Paraoxon-ethyl were applied to all these nine compounds as a substrate. The results revealed that these compounds inhibited the PON1 enzyme activity. The $\mathrm{IC}_{50}$ values of these compounds for PON1 have been outlined in Table 1. The $\mathrm{IC}_{50}$ values were between $1.26 \times 10^{-4} \mathrm{M}$ and $2.31 \times 10^{-4} \mathrm{M}$ for PON1 enzyme activity as shown in Table 1. Among the compounds, Benzidine was found as the most active compound $\left(\mathrm{IC}_{50}=1.26 \times 10^{-}\right.$ $\left.{ }^{4} \mathrm{M}\right)$ for PON1 inhibitory activity (Table 1.). 
Table 1. $\mathrm{IC}_{50}$ values of 4-(dimethylamino)benzaldehyde, 3,5-dinitrosalicylic acid, berylliumsulfate tetrahydrate, urea, sodium azide, iron(II)sulfateheptahydrate, 2-thiobarbituric acid, benzidine, and hydrazinium sulfate.

\begin{tabular}{|l|l|}
\hline Compound & $\mathbf{I C}_{\mathbf{5 0}}$ Values $\left(\mathbf{x 1 0}^{-4} \mathbf{M}\right)$ \\
\hline 4-(Dimethylamino)benzaldehyde & 1,38 \\
\hline 3,5-Dinitrosalicylic Acid & 1,42 \\
\hline Berylliumsulfate tetrahydrate & 2,00 \\
\hline Urea & 1,79 \\
\hline Sodium Azide & 1,82 \\
\hline Iron(II)sulfateheptahydrate & 2,31 \\
\hline 2-Thiobarbituric acid & 1,64 \\
\hline Benzidine & 1,26 \\
\hline Hydrazinium sulfate & 1,86 \\
\hline
\end{tabular}

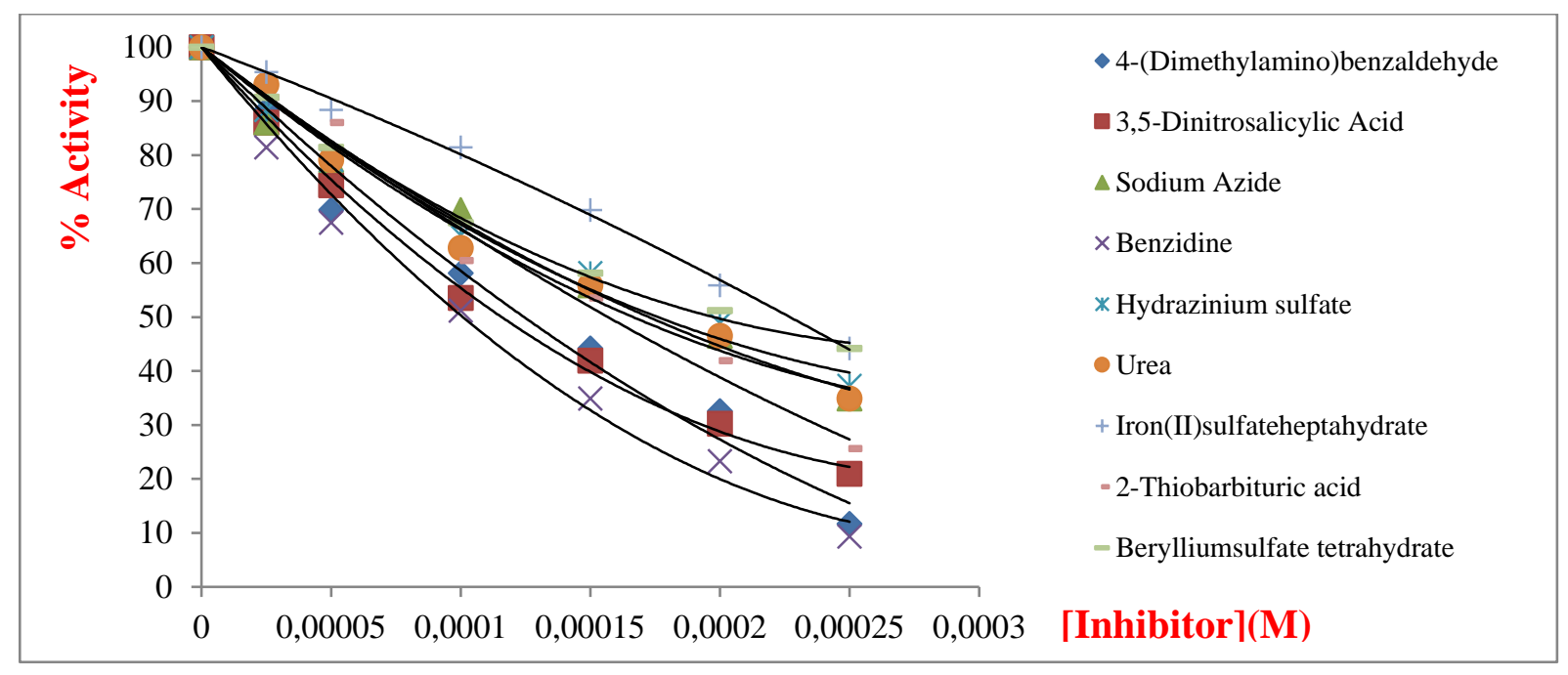

Figure 1. Activity (\%) - [Inhibitor] graph of 4-(dimethylamino)benzaldehyde, 3,5-dinitrosalicylic acid, berylliumsulfate tetrahydrate, urea, sodium azide, iron(II)sulfateheptahydrate, 2-thiobarbituric acid, benzidine and hydrazinium sulfate on PON1.

\section{Discussion}

The literature shows that many enzymes and physiological systems are affected differently by 4-(Dimethylamino)benzaldehyde in different ways and at different levels. Stefek et al. (2000) showed that through a model of streptozotocin induced diabetes in rats, the 4-(Dimethyamino)benzaldehyde reactive material was determined in the rat tail tendon collagen. Time-related relationships of the 4(dimethyamino)benzaldehyde detectable material with tendon mechanical strength and with advanced glycation endproduct related fluorescence were assessed. The effect of the glycation inhibitor 
aminoguanidine was determined. Finally, they showed that the pepsin digest of collagen from diabetic rats could react with 4-(dimethylamino)benzaldehyde under acid conditions to generate a coloured derivative [22]. Moreover, in the study of Mahmoud et al. (1993) aimed to investigate the compound 4(diethylamino)benzaldehyde (DEAB) is a potent inhibitor of cytosolic (class 1) aldehyde dehydrogenase (ALDH) In vitro and can cricumvent cyclophosphamide resistance in murine leukemia cells known to have high content of ALDH. They come to a conclusion that DEAB is a potent inhibitor of ALDH In vivo and has no impact on the mixed function oxidase activity as detected by antipyrine clearance [23].

Yang et al. (2012) showed that an LC-MS/MS method to determine Methoxyamine (the first DNA base-excision-repair inhibitor evaluated in humans) quantitatively in human plasma was developed and validated. In their study, Methoxyamine and methoxyl-d3-amine (Methoxyamine's stable isotope) was derivatized directly in plasma with 4-(N,N-diethylamino)benzoaldehyde under acidic conditions [24].

3,5-Dinitrosalicylic Acid mostly used by Cell Biology, D, Hematology and Histology, Stains \& Dyes researchers for in colorimetric determination of reducing sugars and to analyze glycosidase (glycoside hydrolase) activity by quantitation of enzymatically released reducing sugar [25,26]. Akkarachiyasit et al. (2010) and Alina et al. (2012) studied with 3,5-Dinitrosalicylic Acid for to stop the reaction of amylase activity [27,28]. In addition, Pyrenebutylamidopropylimidazole 1 was synthesized as a sensor for 3,5-dinitrosalicylic acid (3,5-DNSA) and 5-nitrosalicylic acid (5-NSA), among other aromatic carboxylic acids, and $\mathrm{Hg}^{2+}$ among different metal ions in PBS-EtOH solutions by Kumar et. al. (2015) [29]. Many publications on phenolics as potential inhibitors present hugely different assay conditions causing variable estimates of inhibition. On this basis, Nyambe et. al. (2015) optimised the In vitro alpha-amylase inhibition assay and they particularly showed the significance of removal of certain polyphenols after the enzymic reaction when applying 3,5-dinitrosalicylic acid as polyphenols interfere with this reagent [30].

Trace metals such as cadmium, nickel, arsenic, beryllium and chromium (VI) have been recognized as human or animal carcinogens by International Agency for Research on Cancer (IARC). The Carcinogenic ability of these metals relies heavily on factors such as oxidation states and chemical structures. The oxidative concept in metal carcinogenesis suggests that complexes formed by these metals, In vivo, in the vicinity of DNA, catalyze redox reactions, which in turn oxidize DNA. The most important effect of reactive oxygen species in the carcinogenesis progression is DNA damage, resulting in DNA lesions like strand breaks and the sister-chromatid exchange. Mulware et. al. (2013) paper looks through the carcinogenicity of various trace elements [31]. As stated by IARC reports (1993), beryllium inhalation by experimental animals, intratracheal studies on rats, intrabronchial studies on monkeys and intravenous or intramedullary administration to rabbits gave enough proof of carcinogenicity to beryllium and its compounds [32]. That risk of carcinogenesis to the exposure to beryllium and beryllium compounds rose required it to be considered as one of the most carcinogens (group 1) to human by IARC (2002) [33].

Rajagopalan et. al. (1961) studied with twenty-one diverse enzymes. These enzymes were subjected to test for their inclination to inhibition by urea and the nature of the inhibition characterized in each case. The results demonstrated interesting dissimiarities in patterns of urea inhibition and were considered to be related to the mechanism of formation of the enzyme-substrate complex in each case. The competitive inhibition of enzymes by urea was studied under various circumstances in order to beter understand the importance of the inhibition [34].

The use of ferrous sulfate to treat human and rat cells to study dehydroepiandrosterone (DHEA) formation in Alzheimer's disease pathology was reported by researchers. Ferrous sulfate was utilized in a study of the expression of neuronal nicotinic acetylcholine receptors as affected by oxidative stress in PC12 cells. Ferrous sulfate was shown to counteract the inhibitory action of hydrogen peroxide on human cytoplasmic aconitase (iron regulatory protein 1) [35-38]. 
According to the study of Khan et. al. (2014), guided to the bioorganic and medicinal chemist that a simple one step chemistry may generate extra-ordinary bioactive compounds. During Khan et. al. study, they synthesized twenty seven thiobarbituric acid derivatives through a simple one step chemistry and evaluated for their inhibitory potential against urease. Most of these compounds were identified as excellent urease inhibitors [39]. Also, through a robust and quantitative assay, Angelica et. al. (2006) described a new class of DNA polymerase inhibitors that presents some specificity against an enzyme included in resistance to anti-cancer drugs, namely human DNA polymerase eta (hpol $\eta$ ). In their initial screen, the indole thiobarbituric acid (ITBA) derivative 5-((1-(2-bromobenzoyl)-5-chloro-1H-indol-3yl)methylene)-2- thioxodihydropyrimidine-4,6(1H,5H)-dione (ITBA-12) was described as an inhibitor of the Y-family DNA member hpol $\eta$, an enzyme that was related to increased resistance to cisplatin and doxorubicin treatments [40].

Bae et. al. (2014) reported that detection of a range of potent hepatitis C virus (HCV) NS5A inhibitors depended upon the benzidine prolinamide backbone. They set a range of inhibitors based on a new benzidine prolinamide core structure, some of which have quite high level of anti-HCV activity [41]. Moreover, Vetrano et. al. (2005) found that some benzidine derivatives were all competitive inhibitors and where catalase oxidase is significant in activating carcinogens such as benzidine, the capability of the dietary constituents to interfere in this process may be significant in their anti-cancer activity [42].

Hydrazine sulfate (HS), a cost-effective, mass-produced chemical compound observed to be applied in plenty of industrial operations, was primarily suggessted as an anticachexia agent based on its inhibition of the gluconeogenic enzyme, phosphoenolpyruvate carboxykinase (PEP CK) [43,44]. It was further suggested that HS could also, by indirect and non-toxic means, inhibit tumor growth itself as a result of tumor energy (ATP) gain and host energy loss (resulting from cancer-induced excessive gluconeogenesis) being functionally interrelated -as seemed probable- [45]. Early in-vivo papers showed that HS could inhibit weight loss (cachexia) and tumor growth in a variety of transplanted mouse and rat models, without direct cytotoxicity [44-48], could make addition to the antitumor impacts of chemotherapy drugs [49,50], and was free of important adverse effects [51]. These results largely proposed HS as a novel tool of non-toxic cancer chemotherapy [52].

$\mathrm{IC}_{50}$ values were calculated as $1.38,1.42,2,1.79,1.82,2.31,1.64,1.26$, and $1.86 \mathrm{mM}$ for $4-$ (dimethylamino)benzaldehyde, 3,5-dinitrosalicylic acid, berylliumsulfate tetrahydrate, urea, sodium azide, iron(II)sulfateheptahydrate, 2-thiobarbituric acid, benzidine, and hydrazinium sulfate, respectively (Table 1). The chemicals inhibited PON1 at millimolar levels. Benzidine was the strongest inhibitor of all the others.

I presented that 4-(dimethylamino)benzaldehyde, 3,5-dinitrosalicylic acid, berylliumsulfate tetrahydrate, urea, sodium azide, iron(II)sulfateheptahydrate, 2-thiobarbituric acid, benzidine, and hydrazinium sulfate were more effective inhibitors on human serum PON1 activity as seen in Figure1. and Table1. Because there have been no studies observed in the literature on the impacts of these commonly used in the pharmaceutical industry and medical studies compounds on PON1. This study was conducted to purify PON1 from human serum and to see whether concentrations of 4(dimethylamino)benzaldehyde, 3,5-dinitrosalicylic acid, berylliumsulfate tetrahydrate, urea, sodium azide, iron(II)sulfateheptahydrate, 2-thiobarbituric acid, benzidine, and hydrazinium sulfate have any relation with the activity of pure enzyme. It was discovered that these compounds were related to low PON activity. This study gives supportive information for further investigations in relation to the inhibitory impacts of cardiovascular studies on PON1 enzyme, which plays a crucial role in cardiovascular diseases studies. My findings propose that PON activity is negatively modulated by exposure to these compounds that are commonly used in the pharmaceutical industry and medical studies.

In conclusion, it is known that, enzyme inhibition is a significant subject for drug design and biochemical practices [53,54]. My results suggest that the compounds 4-(dimethylamino)benzaldehyde, 3,5-dinitrosalicylic acid, berylliumsulfate tetrahydrate, urea, sodium azide, iron(II)sulfateheptahydrate, 
2-thiobarbituric acid, benzidine, and hydrazinium sulfate will probably be adopted as prospectives for the treatment of cardiovascular diseases. Additionally, these reagents should be considered to be assessed in advance levels in In vivo studies. Because there is no clear evidence that any of these compounds are strongly associated with cardiovascular diseases risk.

\section{Acknowledgement}

The author is grateful to the Siirt University, Faculty of Science and Arts, Biology Department for technical support. The author also greatly appreciate the assistance of Emrah ERIŞ for this paper.

\section{Declaration of Interest}

Some part of the research was presented in 10.National Affinity Techniques Congress (Ayvalık/Balıkesir-TURKEY, 26-28 May 2016) and International Engineering, Science and Education Conference (INESEC) (Diyarbakır-TURKEY 1-3 December 2016) as oral presentation.

\section{References}

[1] B. Mackness, P.N. Durrington, M.I. Mackness, Human Serum Paraoxonase, General Pharmacology: The Vascular System. 31 (1998) 329-336.

[2] N. Ferré, J. Camps, E. Prats, E. Vilella, A. Paul, L. Figuera, J. Joven, Serum paraoxonase activity: A new additional test for the improved evaluation of chronic liver damage, Clinical Chemistry. 48 (2002) 261-268.

[3] N. Forti, J. Diament, Lipoproteínas de alta densidade: aspectos metabólicos, clínicos, epidemiológicos e de intervenção terapêutica. Atualização para os clínicos , Arquivos Brasileiros de Cardiologia . 87 (2006) 671-679.

[4] L.G. Costa, A. Vitalone, T.B. Cole, C.E. Furlong, Modulation of paraoxonase (PON1) activity, Biochemical Pharmacology. 69 (2005) 541-550.

[5] F.G. Santos, M.K. Becker, V.S. Corrêa, D.N. Garcia, S.C. Vale, J.A. Crespo-Ribeiro, C.C. Barros, A. Schneider, The effect of the paraoxonase 1 (PON1) T(-107)C polymorphism on serum PON1 activity in women is dependent on fatty acid intake, Nutrition Research. 36 (2016) 9-15.

[6] T. Suehiro, T. Nakamura, M. Inoue, T. Shiinoki, Y. Ikeda, Y. Kumon, M. Shindo, H. Tanaka, K. Hashimoto, A polymorphism upstream from the human paraoxonase (PON1) gene and its association with PON1 expression, Atherosclerosis. 150 (2000) 295-298.

[7] A.S. Go, D. Mozaffarian, V.L. Roger, E.J. Benjamin, J.D. Berry, W.B. Borden, D.M. Bravata, S. Dai, E.S. Ford, C.S. Fox, S. Franco, H.J. Fullerton, C. Gillespie, S.M. Hailpern, J.A. Heit, V.J. Howard, M.D. Huffman, B.M. Kissela, S.J. Kittner, D.T. Lackland, J.H. Lichtman, L.D. Lisabeth, D. Magid, G.M. Marcus, A. Marelli, D.B. Matchar, D.K. McGuire, E.R. Mohler, C.S. Moy, M.E. Mussolino, G. Nichol, N.P. Paynter, P.J. Schreiner, P.D. Sorlie, J. Stein, T.N. Turan, S.S. Virani, N.D. Wong, D. Woo, M.B. Turner, Executive summary: Heart disease and stroke statistics-2013 update: A Report from the American Heart Association, Circulation. 127 (2013) $143-152$. 
[8] S. Hsu, V.K. Ton, M. Dominique Ashen, S.S. Martin, T.J. Gluckman, P. Kohli, S.D. Sisson, R.S. Blumenthal, M.J. Blaha, A clinician's guide to the ABCs of cardiovascular disease prevention: The johns hopkins ciccarone center for the prevention of heart disease and american college of cardiology cardiosource approach to the million hearts initiative, Clinical Cardiology. 36 (2013) 383-393.

[9] M. Barton, Prevention and endothelial therapy of coronary artery disease, Current Opinion in Pharmacology. 13 (2013) 226-241.

[10] T. Watanabe, S. Haraoka, T. Shimokama, Inflammatory and immunological nature of atherosclerosis, International Journal of Cardiology. 54, Supple (1996) S51-S60.

[11] R.F. Redberg, E.J. Benjamin, V. Bittner, L.T. Braun, D.C. Goff Jr., S. Havas, D.R. Labarthe, M.C. Limacher, D.M. Lloyd-Jones, S. Mora, T.A. Pearson, M.J. Radford, G.W. Smetana, J.A. Spertus, E.W. Swegler, ACCF/AHA 2009 performance measures for primary prevention of cardiovascular disease in adults: a report of the American College of Cardiology Foundation/American Heart Association Task Force on Performance Measures (Writing Committee to Develop Performanc, J Am Coll Cardiol. 54 (2009) 1364-1405.

[12] S.-Y. Eom, Y.-S. Kim, C.-J. Lee, C.-H. Lee, Y.-D. Kim, H. Kim, Effects of Intronic and Exonic Polymorphisms of Paraoxonase 1 (PON1) Gene on Serum PON1 Activity in a Korean Population, J Korean Med Sci. 26 (2011) 720-725.

[13] T. Bhattacharyya, N. SJ, T. EJ, et al, RElationship of paraoxonase 1 (pon1) gene polymorphisms and functional activity with systemic oxidative stress and cardiovascular risk, JAMA. 299 (2008) $1265-1276$.

[14] T. Ito, H. Yasue, M. Yoshimura, S. Nakamura, M. Nakayama, Y. Shimasaki, E. Harada, Y. Mizuno, H. Kawano, H. Ogawa, Paraoxonase gene Gln192Arg (Q192R) polymorphism is associated with coronary artery spasm, Human Genetics. 110 (2001) 89-94.

[15] M. Wang, X. Lang, L. Zou, S. Huang, Z. Xu, Four genetic polymorphisms of paraoxonase gene and risk of coronary heart disease: A meta-analysis based on 88 case-control studies, Atherosclerosis. 214 (2011) 377-385.

[16] M.I. Mackness, S. Arrol, C. Abbott, P.N. Durrington, Protection of low-density lipoprotein against oxidative modification by high-density lipoprotein associated paraoxonase, Atherosclerosis. 104 (1993) 129-135.

[17] a I. Rupérez, O. López-Guarnido, F. Gil, J. Olza, M. Gil-Campos, R. Leis, R. Tojo, R. Cañete, a Gil, C.M. Aguilera, Paraoxonase 1 activities and genetic variation in childhood obesity., The British Journal of Nutrition. 110 (2013) 1639-47.

[18] M. Aviram, M. Rosenblat, C.L. Bisgaier, R.S. Newton, S.L. Primo-Parmo, B.N. La Du, Paraoxonase inhibits high-density lipoprotein oxidation and preserves its functions. A possible peroxidative role for paraoxonase., The Journal of Clinical Investigation. 101 (1998) 1581-1590. 
[19] S. Sinan, F. Kockar, O. Arslan, Novel purification strategy for human PON1 and inhibition of the activity by cephalosporin and aminoglikozide derived antibiotics., Biochimie. 88 (2006) 56574.

[20] N. Gençer, O. Arslan, Purification human PON1Q192 and PON1R192 isoenzymes by hydrophobic interaction chromatography and investigation of the inhibition by metals., Journal of Chromatography. B, Analytical Technologies in the Biomedical and Life Sciences. 877 (2009) $134-40$.

[21] K.N. Gan, A. Smolen, H.W. Eckerson, B.N. La Du, Purification of human serum paraoxonase/arylesterase. Evidence for one esterase catalyzing both activities., Drug Metabolism and Disposition: The Biological Fate of Chemicals. 19 (1991) 100-106.

[22] M. Stefek, A. Gajdosik, A. Gajdosikova, L. Krizanova, p-dimethylaminobenzaldehyde-reactive substances in tail tendon collagen of streptozotocin-diabetic rats: Temporal relation to biomechanical properties and advanced glycation endproduct (AGE)-related fluorescence, Biochimica et Biophysica Acta - Molecular Basis of Disease. 1502 (2000) 398-404.

[23] M.I. Mahmoud, J.J. Potter, O.M. Colvin, J. Hilton, E. Mezey, Effect of 4(diethylamino)benzaldehyde on ethanol metabolism in mice., Alcoholism, Clinical and Experimental Research. 17 (1993) 1223-1227.

[24] S. Yang, P. Savvides, L. Liu, S.L. Gerson, Y. Xu, Development and validation of an LC-MS/MS method for pharmacokinetic study of methoxyamine in phase I clinical trial, Journal of Chromatography B: Analytical Technologies in the Biomedical and Life Sciences. 901 (2012) $25-33$.

[25] G.L. Miller, Use of Dinitrosalicylic Acid Reagent for Determination of Reducing Sugar, Analytical Chemistry. 31 (1959) 426-428.

[26] J.F. Robyt, W.J. Whelan, Reducing value methods for maltodextrins. I. Chain-length dependence of alkaline 3,5-dinitrosalicylate and chain-length independence of alkaline copper., Analytical Biochemistry. 45 (1972) 510-516.

[27] S. Akkarachiyasit, P. Charoenlertkul, S. Yibchok-Anun, S. Adisakwattana, Inhibitory activities of cyanidin and its glycosides and synergistic effect with acarbose against intestinal-glucosidase and pancreatic-amylase, International Journal of Molecular Sciences. 11 (2010) 3387-3396.

[28] C. Alina, P. Vasilica, M. Eugen, F. Sanda, Spectrophotometric Studies About Amylase Activity in Starch Hydrolysis Reaction, (2012) 1-16.

[29] A. Kumar, A. Pandith, H.-S. Kim, Pyrenebutylamidopropylimidazole as a multi-analyte sensor for 3,5-dinitrosalicylic acid and Hg2+ ions, JOURNAL OF LUMINESCENCE. 172 (2016) 309316.

[30] H. Nyambe-Silavwe, J.A. Villa-Rodriguez, I. Ifie, M. Holmes, E. Aydin, J.M. Jensen, G. 
Williamson, Inhibition of human alpha-amylase by dietary polyphenols, JOURNAL OF FUNCTIONAL FOODS. 19 (2015) 723-732.

[31] S.J. Mulware, Trace elements and carcinogenicity: a subject in review, 3 BIOTECH. 3 (2013) 85-96.

[32] P. Boffetta, Carcinogenicity of trace elements with reference to evaluations made by the International Agency for Research on Cancer., Scandinavian Journal of Work, Environment \& Health. 19 Suppl 1 (1993) 67-70.

[33] Some traditional herbal medicines, some mycotoxins, naphthalene and styrene., IARC Monographs on the Evaluation of Carcinogenic Risks to Humans / World Health Organization, International Agency for Research on Cancer. 82 (2002) 1-556.

[34] K. V Rajagopalan, Competitive Inhibition of Enzyme by Urea , 236 (1961).

[35] C. a S. Rn, Sigma brand products are sold through Sigma-Aldrich, Inc. Sigma-Aldrich, Inc. warrants that its products conform to the information contained in this and other Sigma-Aldrich publications. Purchaser must determine the suitability of the product(s) for thei, Solutions. 173 (2003) 6628.

[36] R.C. Brown, Z.Q. Han, C. Cascio, V. Papadopoulos, Oxidative stress-mediated DHEA formation in Alzheimer's disease pathology, NEUROBIOLOGY OF AGING. 24 (2003) 57-65.

[37] Z.Z. Guan, X. Zhang, M. Mousavi, J.Y. Tian, C. Unger, A. Nordberg, Reduced expression of neuronal nicotinic acetylcholine receptors during the early stages of damage by oxidative stress in PC12 cells, JOURNAL OF NEUROSCIENCE RESEARCH. 66 (2001) 551-558.

[38] X. Brazzolotto, J. Gaillard, K. Pantopoulos, M.W. Hentze, J.M. Moulis, Human cytoplasmic aconitase (iron regulatory protein 1 ) is converted into its $\{[\} 3 \mathrm{Fe}-4 \mathrm{~S}]$ form by hydrogen peroxide in vitro but is not activated for iron-responsive element binding, JOURNAL OF BIOLOGICAL CHEMISTRY. 274 (1999) 21625-21630.

[39] K.M. Khan, F. Rahim, A. Khan, M. Shabeer, S. Hussain, W. Rehman, M. Taha, M. Khan, S. Perveen, M.I. Choudhary, Synthesis and structure-activity relationship of thiobarbituric acid derivatives as potent inhibitors of urease., Bioorganic \& Medicinal Chemistry. 22 (2014) 411923.

[40] M.D. Angelica, Y. Fong, NIH Public Access, October. 141 (2008) 520-529.

[41] I.H. Bae, J.K. Choi, C. Chough, S.J. Keum, H. Kim, S.K. Jang, B.M. Kim, Potent hepatitis C virus NS5A inhibitors containing a benzidine core, ACS Medicinal Chemistry Letters. 5 (2014) $255-258$.

[42] A.M. Vetrano, D.E. Heck, T.M. Mariano, V. Mishin, D.L. Laskin, J.D. Laskin, Characterization 
of the oxidase activity in mammalian catalase, Journal of Biological Chemistry. 280 (2005) 35372-35381.

[43] J. Gold, Proposed treatment of cancer by inhibition of gluconeogenesis., Oncology. 22 (1968) 185-207.

[44] J. Gold, Inhibition of Walker 256 intramuscular carcinoma in rats by administration of hydrazine sulfate., Oncology. 25 (1971) 66-71.

[45] J. Gold, Cancer cachexia and gluconeogenesis., Annals of the New York Academy of Sciences. 230 (1974) 103-110.

[46] J. Gold, Inhibition by hydrazine sulfate and various hydrazides, of in vivo growth of Walker 256 intramuscular carcinoma, B-16 melanoma, Murphy-Sturm lymphosarcoma and L-1210 solid leukemia., Oncology. 27 (1973) 69-80.

[47] V.M. Dilman, V.N. Anisimov, A.I. Kolosov, L.N. Bulovskaya, On the relationship between the activity of acetylation, growth of experimental tumors and efficacy of their suppression by hydrazine sulphate., Oncology. 33 (1976) 219-221.

[48] B. Grubbs, W. Rogers, I. Cameron, Total parenteral nutrition and inhibition of gluconeogenesis on tumor-host responses., Oncology. 36 (1979) 216-223.

[49] J. Gold, Enhancement by hydrazine sulfate of antitumor effectiveness of cytoxan, mitomycin C, methotrexate and bleomycin, in walker 256 carcinosarcoma in rats., Oncology. 31 (1975) 44-53.

[50] J. Gold, Potentiation by clofibrate of in-vivo tumor inhibition by hydrazine sulfate and cytotoxic agents, in Walker 256 carcinosarcoma., Cancer Biochemistry Biophysics. 3 (1978) 41-45.

[51] J. Gold, Hydrazine sulfate: A current perspective, Nutrition and Cancer. 9 (1987) 59-66.

[52] J. Gold, Inhibition of gluconeogenesis at the phosphoenolpyruvate carboxykinase and pyruvate carboxylase reactions, as a means of cancer chemotherapy., Oncology. 29 (1974) 74-89.

[53] M.O. Kaya, O. Arslan, O.O. Guler, A new affinity method for purification of bovine testicular hyaluronidase enzyme and an investigation of the effects of some compounds on this enzyme., Journal of Enzyme Inhibition and Medicinal Chemistry. 30 (2015) 524-7.

[54] Mustafa Oğuzhan Kaya, Yesim Kaya, Gülsah Çelik, Figen Kurtulus, Oktay Arslan, Özen Özensoy Güler, Differential in vitro inhibition studies of some cerium vanadate derivatives on Xanthinelnoxidase, 6366 (2015). 